\title{
Mošé ibn `Ezrá: El poema de los dos exilios
}

\author{
Ángeles NAVARRO PEIRO \\ Universidad Complutense, Madrid \\ En memoria de Antonio Peral, \\ profesor y amigo
}

En su estudio sobre la obra poética de Mošé ibn 'Ezrá, D. Pagis ${ }^{1}$ incluyó entre los poemas de queja contra las adversidades y el destino (širé teluná) el poema de dicho autor, núm. 20 en la edición de Brody ${ }^{2}$. Las poesías de este tipo abundan en el diván del poeta, ya que sus circunstancias vitales propiciaron el cultivo de este género. Según indica I. Levin ${ }^{3}$, posiblemente Mošé ibn 'Ezrá escribió más poemas de queja que ningún otro poeta hebreo de Sefarad.

La clasificación de un poema como perteneciente a un género poético determinado no siempre resulta fácil, especialmente cuando nos encontramos con un texto largo y complejo, compuesto por diversas unidades temáticas.

R. Brann estudió, analizó y tradujo al inglés varios poemas del diván de Mošé ibn 'Ezrá que Pagis había clasificado como «poemas de queja» y utilizó para calificarlos la expresión inglesa «friendship/lyrical complaint poem», pues la mayor parte de ellos se dirigen a los amigos del poeta. Consideró además que tal tipo

\footnotetext{
1 Secular Poetry and Poetic Theory: Moses ibn Ezra and his Contemporaries [en hebreo] (Jerusalén 1970) pág. 283 nota 2.

${ }^{2}$ MOŠEH IBN 'EzRA, Širé ha-hol, 3 vols.: vols. I-II, ed. H. BROdy (Berlín 19351942; reimpr. Jerusalén 1977); vol. III, ed. D. PAGIS (Jerusalén 1977).

${ }^{3}$ The Embroidered Coat: The Genres of Hebrew Secular Poetry in Spain [en hebreo] (Tel Aviv 1994) pág. 249.
} 
de composiciones responde a una mezcla de géneros entre el panegírico (šir šébah) y el poema de queja ${ }^{4}$.

Sin embargo, en este caso, a pesar de que se trata de un poema largo y complejo, la queja del poeta recorre prácticamente todas las líneas de su poesía, y aunque también aparezcan expresiones de nostalgia y cariño hacia sus amigos, no entra dentro de los cánones del panegírico clásico árabe o hebreo andalusí. Por otra parte, D. Pagis llama a algunos poemas de queja «epistolares», ya que se incluían en cartas ${ }^{5}$. El poema que nos ocupa formaba asimismo parte de una carta, pues, como luego veremos, así se dice explícitamente en el encabezamiento en judeo-árabe que aparece en el diván.

Unos ochenta poemas de queja forman parte del diván de Mošé ibn 'Ezrá y en ellos se encuentra como tema recurrente su tristeza y soledad en el exilio por tierras cristianas. Sin embargo, no es usual que aparezcan en ellos juntamente alusiones a sus dos exilios: el que sufrió en su patria, Granada, cuando los invasores almorávides derrotaron en el año 1090 a 'Abd Allāh, rey de Granada, lo cual provocó la emigración de sus hermanos y de sus mejores amigos; y el de fuera de ella, cuando el propio poeta se vio obligado a exiliarse en tierras cristianas. En el poema que nos ocupa el autor realiza varios saltos en el tiempo poniendo de relieve los momentos más difíciles y amargos de ambos exilios. D. Pagis ${ }^{6}$ cita varias veces esta composición cuando trata de la aparición de elementos de carácter autobiográfico en los poemas de queja de Mošé ibn 'Ezrá.

En cuanto a su estructura, responde a la de la casida árabe, ya que es un poema métrico con rima común para todos sus versos y de metro ha-šalem (árabe kämil).

Hemos considerado oportuno presentar la traducción castellana de dicho texto, ya que no tenemos noticia de ninguna traducción a lengua occidental. Desgraciadamente ese es el caso de la mayor parte de los poemas recogidos en el diván de Mošé ibn 'Ezrá, pues todavía no existe una versión completa de su obra poética ${ }^{7}$.

\footnotetext{
${ }^{4}$ R. BRAnN, Structure and Meaning in the Secular Poetry of Moshe ibn Ezra (Nueva York 1981) págs. 33-36.

${ }^{5}$ PAgis Secular Poetry pág. 286.

${ }^{6}$ Pagis Secular Poetry págs. 292-307.

${ }^{7}$ Poemas suyos se encuentran traducidos a varias lenguas, sobre todo al inglés y al castellano, en diversos estudios y antologías. Son numerosos los artículos dedicados a diversos aspectos de la obra del poeta, así como los capítulos que se
} 
Hemos omitido la anotación de las alusiones y citas bíblicas por ser demasiado numerosas, lo cual entorpecería la lectura del texto, ya que aparecen prácticamente en todos los versos del poema. Veamos ya el texto para pasar luego al comentario de su contenido.

\section{EL TEXTO}

\section{[POEMA DE LOS DOS EXILIOS]}

Del capítulo de la separación y de la soledad. En él se dirigió a sus amigos de Occidente, Dios los favorezca, quejándose en una carta por su ausencia y describiendo su mala situación en Castilla, y dijo: «Šabti vetaltalé zemán lo šabu ...»

Tengo el pelo blanco, mas el cabello del Tiempo no ha encanecido, y los días del exilio han vuelto a la juventud.

Después de haberse ajado, ha sentido placer la madre de la separación y los hijos del deseo se han enamorado.

$\mathrm{Al}$ volverse muy cortos los pasos de mis años, las lindes del sendero de mis penas como el mar se han ensanchado.

Los oleajes de la vejez asimismo me han cercado, y se ha quedado seca la fuente de la juventud.

5 Digo a los que me reprenden: «Tened calma conmigo hasta que me lamente», y a los que me recriminan: «iCesad!».

Cesad hasta que ronde por lugares que tan solo por las llamas de mi corazón y el llanto de mis ojos quedaron asolados.

Parecían ciudades destruidas por las que no pasaba pie humano y nadie las habitaba.

Después de haberse desplegado en ellas las alas de la amistad y de haberse arrastrado por ellas los vuelos del amor,

los ejércitos de gacelas disminuyeron en su interior, mientras, por el [contrario, en sus cuatro lados se multiplicaron los chacales para lamentarse.

10 Yo gritaba, mas cómo mudos me iban a responder, clamaba, pero cómo sordos iban a prestar atención.

le dedican en libros que tratan sobre la literatura hispanohebrea o sobre la poesía hebrea andalusí en particular. También contamos con traducciones y estudios de grupos de poemas que responden a una temática concreta como, por ejemplo, el libro ya citado de BranN Structure and Meaning, o el de Á. NAVARro PEIRO, El Tiempo y la Muerte: Las elegías de Mošeh ibn 'Ezra'(Granada 1994). 
Tan sólo se me daban a conocer por el aroma a bálsamo de las moradas que habían abandonado.

Hasta que se cubrieran de hierba las piedras de sus ruinas yo seguiría lamentándome, se regarían con el aguacero de mi llanto ${ }^{8}$.

Se me heló la sangre del corazón ante la mención del exilio [nedod], también los ríos de mis ojos como un dique se irguieron.

No me ayudaron estos y cada vez que les pedía:

«Con vuestros bienes sobornad en mi favor», no querían hacerlo.

15 Sin embargo, al ver que los carros de viaje corrían hacia mí y los caballos del exilio [nedod] se acercaban, se rompieron los odres de sangre de mis ojos, los cuales se derramaban día a día con la sangre de mi hígado.

Decid: ¿Acaso de las fuentes del océano extraían, o de los abrevaderos de mi cabeza sacaban el llanto? ¿O había en mi interior agua en llamas que, cuando fluía, mi vigoroso rostro se abrasaba?

Se me rompió el corazón cuando alguien gritó: «Disponeos, partid». También los miembros de mi cuerpo se quebraron

20 el día en el que para lamentarse por mi exilio [nudí] se concertaron mis hermanos y para llorar acudieron mis amigos.

Se golpeaban el pecho llorando por mí mujeres que no eran mencionadas ni designadas por sus nombres.

Zureaban con el zureo de las palomas y sus mejillas, semejantes al hilo escarlata, se volvieron como el lino blanco.

Con lengua suave tiraban del borde de mi corazón y sujetaban mi alma con halagüeñas expresiones:

«No abandones a los pedazos de tu corazón que de la cantera de tu amor han sido tallados.

25 Ten calma, en verdad los que guardan la alianza del amor yacen con sus amigos aún entre llamas de fuego».

Contesté: «Partiré para mostrar a mis amigos mis más excelsos loores que anhelaban.

Vagaré buscando lo que perdí, lo que de entre mis brazos los azares capturaron.

${ }^{8}$ El verso núm. 12 aparece citado por Ibn 'Ezrá en su obra de poética Kitab al-muhädara wal-mudakara como ejemplo de hipérbole, ya que, según indica, la permanencia ante las ruinas es tan larga que se refiere a un tiempo sin fin, como lo sería el tiempo necesario para hacer brotar hierba de las piedras regándolas con el llanto. Cito por la ed. del Kitab de M. V. Abumalham Mas (Madrid: CSIC, 1985) vol. II pág. 262. 
Cuando vea a mis hermanos, se regocijarán todos mis íntimos, y quedarán confundidos los que me odian».

Sin embargo, el hombre proyecta, mas el Tiempo desbarata todos los planes que se habían hecho.

30 Nada conoce acerca de él mi mente, tan sólo que los que amaban se han pasado al odio.

Me ha hecho rodar hacia una tierra en la que se han apagado las luces de mi inteligencia.

Los astros de mi mente con las tinieblas de los de ciencia balbuciente y de habla incomprensible se han oscurecido.

Llegué a un territorio de maldad, a un pueblo con el que Dios está airado y a quien todo lo que existe maldice.

Entre asnos salvajes que aman al malvado, pero [ 'abal] ${ }^{9}$ acechan para derramar la sangre del que es recto e íntegro.

35 Han elegido su camino los que viven con ellos, los que con ellos se han unido y mezclado.

Se han asimilado a ellos y a sus obras hasta el punto de ser empadronados y censados con ellos.

Durante los días de su juventud apacentaron en el huerto de la rec[titud, mas cuando han envejecido talan árboles en el bosque de la vanidad. Ellos dispusieron las flechas de los azares en la cuerda, dispararon contra mis más íntimas esperanzas.

Preguntad a los sabios que desaparecieron, aquellos cuyos testimonios viven, aunque ellos se pudrieran;

40 inquirid también en los libros de sabiduría, pues sin boca la verdad expresan,

¿han planeado los hermanos un mal como este?, ¿han tenido noticia de las tramas que urdieron?; ¿se han burlado los hijos de los padres como de mí se han burlado mis hijos y me han atacado? Vientos perfumados que al atardecer pasáis por Granada ${ }^{10}$,

\footnotetext{
${ }^{9}$ El verso núm. 34 aparece en el Kitab (vol. II pág. 311) en el capítulo dedicado a al-istittna' o 'restricción', como ejemplo de utilización de la partícula 'abal.

${ }^{10}$ En el texto hebreo bet rimón, expresión que aparece en 2 Reyes 5:18. Según el uso de la escuela hebrea andalusí, Mošé ibn 'Ezrá utiliza expresiones bíblicas para indicar los topónimos. En el caso de Granada, en hebreo rimón, además de la que acabamos de mencionar, encontramos, por ejemplo: rimón péres (BRODY núm. 263 lín. 41) según Núm 33:19-20; hadar rimón (BRODY núm. 67 v. 32) que no tiene un paralelo exacto en la Biblia, pero que indudablemente recuerda el nombre propio Hadad Rimón que aparece en Zac 12:11; etc.
} 
y sobre el monte Senir ${ }^{11}$ sopláis,

cerneos un poco sobre mis hermanos y dulcemente

traed a mi nariz su perfume, traedlo.

45 Traed los saludos de quienes habitan en el rincón del mar, pues a mi alma complacen los hijos de Occidente ${ }^{12}$.

A ellos envío mis quejas sobre

una nube ligera, sobre las alas de un querub cabalgan,

ya que olvidaron mis amores, me traicionaron,

no se han afligido con mi quebranto ni se han dolido,

no trajeron mi suerte a su memoria, ni

le prestaron atención, no se apenaron,

no me han consolado por boca de la pluma,

ni los labios de una carta han pronunciado palabras de saludo.

50 Tengo hambre y sed de esos traidores

que no sienten sed ni hambre de mí.

Lloro por la época de la amistad, pues del glorioso tiempo

de la mocedad días de juventud fueron cortados,

y por la belleza de las noches claras como la luz

del sol, más que el ágata brillantes en su compañía.

Volaron y se han enrollado como un libro sobre

las líneas escritas de mis alegrías.

Espero ver su imagen en el lecho por medio

del sueño y en las fantasías que suspiran por ellos;

55 mas muralla inaccesible es el sueño

a mis ojos, demasiado elevada para poderla alcanzar.

Mi corazón es muy avaro en consolarse por su exilio,

pero mis ojos son generosos en lágrimas.

Haría llorar a los ejércitos de lo alto; si tuvieran ojos, se consumirían entonces por el llanto.

Se disuelve como agua mi corazón al recordar un poco de su bondad y mis entrañas como cera se derraman.

Por vida del cariño que por ellos siento, pues corre mansamente el agua de la fuente de mi amor y no engaña,

\footnotetext{
${ }^{11}$ Nombre de un monte del Líbano según Deut 3:9, Ez 27:5, Cant 4:8 y 1 Cr 5:23. En este caso parece que el poeta utiliza el topónimo para referirse a Sierra Nevada. En el poema núm. 67 de la edición de BRODY (vs. 31-32) también encontramos el término Senir en relación con Granada, pero en dicho lugar parece referirse al río Genil.

${ }^{12}$ En el texto hebreo ha-ma 'arab; Mošé ibn 'Ezrá utiliza el término con el sentido del árabe El Magreb y referido a al-Andalus.
} 
60 qué preciosos son los confines de Oriente ${ }^{13}$ cuando recuerdo sus obras, qué agradables, poemas más dulces que la miel de su lengua, palabras que de su áloe fueron robadas.

Como ley establezco su amor hasta el día en que salgan las estrellas de sus luminares los cuales se han velado.

\section{COMENTARio}

Pasemos ahora a examinar las unidades que forman el poema.

\subsection{Versos $1-5$}

Los primeros versos del poema se sitúan en el presente, en la realidad actual del poeta: exilio en tierra extraña, soledad y vejez. En el v. 1 aparece ya el motivo del «tiempo» (zemán), tan recurrente en la poesía de Mošé ibn 'Ezrá, y el del exilio, indicado por la palabra nedudim. Ese término, cuyas principales acepciones son 'vagabundeo', 'migración', 'éxodo', etc., junto con nedod que tiene un significado similar, son las palabras más utilizadas por nuestro autor para dar cuenta de la condición del hombre sin patria.

En primer lugar se trata de expresar un movimiento continuo que no da lugar al descanso, un movimiento que aleja cada vez más al poeta de lo que ama, y un movimiento que tiene lugar en tierra extraña, en el exilio. Asimismo utiliza el poeta otras formas derivadas de la raíz $n . d . d$, o de la raíz $n . d$ con ella emparentada, para indicar diversos matices de esta acción o situación ${ }^{14}$. De ahí que traduzcamos nedudim o nedod por 'exilio'.

La idea del exilio como movimiento sin descanso se encuentra claramente expresada en los siguientes versos pertenecientes a otro poema de Mošé ibn 'Ezrá:

Hasta dónde serán enviados mis pies en el destierro, pues aún no han hallado reposo.

Desenvainó el tiempo la espada de la separación

${ }^{13}$ En el texto hebreo mizrah. El poeta utiliza este término para referirse a Castilla, donde se encuentra, en contraposición con ha-ma 'arab 'el Occidente', es decir, al-Andalus.

${ }^{14}$ Sobre este tema, véase el artículo de Á. NAVArRo PEIRO, «El tema del exilio en la poesía de Mošeh ibn 'Ezra», Miscelánea de Estudios Árabes y Hebreos 44 (1995) págs. 47-59. 
para perseguirme, blandió el hacha del exilio [ha-nedod] para [alejarme.

Volvió a sus azares en contra mía para que no me quedara quieto en mi puesto y como una sombra huyera día a día ${ }^{15}$.

\subsection{Versos $6-12$}

En el v. 6 realiza el poeta la transición a la siguiente unidad del poema recordando los lugares que en Granada frecuentaba con sus amigos y a continuación se traslada Mošé ibn 'Ezrá al pasado remoto, la época en la que, a consecuencia de la invasión almorávide, emigraron sus hermanos y la mayor parte de sus amigos, quedándose él como un exiliado en su propia patria.

Esa sensación de abandono del que se siente extraño en su tierra aparece también en otros textos del poeta como, por ejemplo, en una carta que Brody considera escrita en Granada entre los años 1091 y 1095 donde leemos:

Me quedé en Granada como extranjero residente en el país. En una ciudad, cuya gloria y bullicio se abatió, me he quedado como pájaro que vaga alejado de su nido, entre una generación desviada y pervertida, como ave fugitiva, nidada dispersa. La huida me fue imposible y no hay quien me busque ni me recuerde; observo a la derecha y miro y no hay quien me conozca ${ }^{16}$.

Y en otra carta, escrita también desde Granada, así se expresa:

Mis ojos fluyen y llevo mi carne entre los dientes pues me he quedado solo en mi patria sin nadie conmigo. En ella soy considerado como extranjero residente y no veo a mi alrededor un varón de mi familia ni de la casa de mi padre ${ }^{17}$.

\subsection{Versos $13-28$}

En el v. 13 encontramos de nuevo una transición que nos lleva desde ese vago pasado remoto a un tiempo concreto dentro del mismo pasado, el momento en el que el propio poeta tuvo que emigrar de al-Andalus. Los vs. 14-28 expresan sus sentimientos en esa circunstancia: por una parte, dolor al tener que abandonar a

\footnotetext{
${ }^{15}$ BRODY núm. 67 vs. $1-3$.

${ }^{16}$ BRODY núm. 263 líns. 41-48.

${ }^{17}$ BRODY núm. 262 líns. 74-75.
} 
los pocos amigos que aún le quedaban en Granada; y por otra, la esperanza de volver a ver a sus amigos ya exiliados.

Sin embargo, hay aquí cierta contradicción con lo expresado por Ibn 'Ezrá en los textos anteriormente citados en los que afirmaba haberse quedado completamente solo. Por otra parte, en el poema que nos ocupa el poeta envía un mensaje a sus amigos que están en Granada (vs. 45-50). ¿Se trata de los que se habían quedado allí? ¿Habían vuelto después de haber emigrado? Esas preguntas quedan sin respuesta, ya que, como hemos indicado, los textos del poeta parecen contradictorios. Sin embargo, no sería extraño que parte de ellos se quedara en al-Andalus al igual que lo hicieron muchos otros judíos, al menos hasta el tiempo de la invasión almohade.

También en este otro fragmento recuerda Mošé ibn 'Ezrá el momento concreto de su exilio y tampoco parece que estuviera solo, incluso sus hijos estaban con él:

Después de que los días de la juventud pasaron como una sombra y los pasos de mis años se han acortado, me grita el vagabundeo: «iEh tú, el que vive tranquilo, levanta!». $\mathrm{Y}$ ante su clamor retiñeron mis oídos.

Me levanté con el corazón trémulo y salí errante, mientras mis hijos imploraban a Dios.

Eran la fuente de mi vida, cómo podría vivir sin ellos, faltándome la luz de mis ojos.

El Tiempo me condujo a una tierra en la que se espantaron mis ideas y pensamientos:

un pueblo de labios balbucientes, de idioma incomprensible, que al contemplar sus rostros se abatía el mío ${ }^{18}$.

\subsection{Versos $29-42$}

Una nueva transición se produce en los vs. 29 y 30 y a través del motivo del «tiempo», el cual anula las esperanzas y desbarata los planes del hombre, nos introduce en el pasado reciente. La nueva vida en tierras cristianas resulta decepcionante para el poeta. Echa continuamente en falta la cultura y el refinamiento de sus amigos andalusíes. Su soledad es intelectual en este caso, pues los judíos de los países cristianos tenían, en su opinión, un nivel cultural bastante inferior.

${ }^{18}$ BRODY núm. 145 vs. 1-6. 
No sólo en este poema elige el término hebreo peraim 'onagros o asnos salvajes', para calificarlos. Así se expresa, por ejemplo, en estos versos pertenecientes a otras composiciones suyas:

Asnos sin brida que caballos

cebados y potentes creen ser.

Con ellos parezco un hombre entre onagros,

un león en compañía de monos y pavos reales ${ }^{19}$;

y también:

Cuando la vida errante, cruel y apresurada, me embriaga con el vino de la nostalgia,

me siento desolado entre onagros,

sin nadie que mire por mi vida, ni me recuerde.

Hacia la izquierda llamo, no hay quien responda;

me vuelvo a la derecha, ninguno me reconoce ${ }^{20}$.

$\mathrm{Al}$ parecer el poeta reprocha a sus antiguos amigos el haberse adaptado a la sociedad judía que habitaba en las tierras que los acogieron después de su emigración de al-Andalus.

\subsection{Versos 43-58}

En el v. 43 se realiza otra transición que nos lleva al presente. Sus seres queridos no se acuerdan de él, no le escriben. Llora por la pérdida de la felicidad que la amistad proporciona. La única esperanza que le queda es la posibilidad de verlos en sueños.

No es inusual entre los poetas árabes y hebreos andalusíes, y en Mošé ibn 'Ezrá en particular, la utilización de imágenes y motivos de la poesía amorosa en los poemas de amistad. La figura del «mensajero» aparece frecuentemente en los poemas de amor $\mathrm{y}$, aunque pueda representarse por medio de una persona, es habitual que ese papel lo desempeñen las fuerzas de la naturaleza. Cuando se han de cubrir grandes distancias, el mensajero suele ser el viento o la brisa, rịh en árabe y rúah en hebreo, y así lo encontramos en los vs. 43-45 de nuestro texto.

También aparece en otros poemas como en los siguientes versos que dirigió el poeta a su hermano Yehudá:

${ }^{19}$ BROdY núm. 100 vs. 5-6.

${ }^{20}$ BRODY núm. 101. 
Oh viento, que pasas al amanecer sobre el perfume de nuestros nardos y nuestras rosas, lleva nuestros saludos a los hermanos que traicionaron, pues en ir se retrasarían nuestras palomas ${ }^{21}$.

También las palomas llevan a veces el mensaje:

Palomas que cual nube voláis hacia Occidente, por vida del amor os conjuro

para que llevéis mis saludos a los amigos que están lejos, pero que entre mis costados plantaron su tienda ${ }^{22}$;

o lo hace un río:

Río que fluye hacia la tierra

donde mora el amado, llévale mis saludos ${ }^{23}$.

Los motivos del «sueño»y del «insomnio», por ejemplo, que en el poema que nos ocupa aparecen en los vs. 54-55, son motivos típicos de los poemas de amor y así lo expresa Ibn Hazm de Córdoba en El collar de la paloma:

El insomnio es otro de los accidentes de los amantes. Los poetas han sido muy prolijos en describirlo; suelen decir que son «apacentadores de las estrellas» y se lamentan de lo larga que es la noche ${ }^{24}$

Así, por ejemplo, en un poema epistolar dirigido a su hermano Yosef, Mošé ibn 'Ezrá le manifiesta cuánto le añora y se refiere a sí mismo en tercera persona con estas expresiones:

Huye el sueño por la noche retirando su luz y desplegando la tienda de las tinieblas.

Pastorea las tropas de lo alto y contempla las estrellas del alba como rosas en un jardín floreciente ${ }^{25}$.

El motivo del «sueño», que en la poesía amorosa permite ver la imagen del ser amado, el cual se aparece durante el descanso nocturno, es bastante frecuente en los poemas de queja de Mošé ibn 'Ezrá, ya que lo presenta como la única esperanza del poeta para

\footnotetext{
${ }^{21}$ BRODY núm. 153 vs. 19-20.

22 BRODY núm. 175 vs. 44-45.

23 BRODY núm. 123 v. 1.

${ }^{24}$ IBN HAZM DE CÓRDOBA, El collar de la paloma, trad. E. GARCía GÓMEZ (3a ed., Madrid: Alianza Editorial, 1971) pág. 113.

${ }^{25}$ BRODY núm. 64 vs. 5-6.
} 
poder ver a los seres queridos ausentes, como en estos versos pertenecientes a otro poema epistolar dirigido a sus hermanos:

De pronto me encuentro con los fantasmas de los amigos que [abandoné, los cuales andan vagando en la oscuridad de la noche.

Las trampas de mis pensamientos están tendidas para ellos y la red del sueño sobre mi lecho de dolor extiendo.

Cómo vagan por el desierto, cómo se han disfrazado con la máscara del manto de la noche. Yo no lo sabía.

Visitaron mi lecho una noche en la que, durante toda ella hasta el alba, me hartaba de dar vueltas a causa de mi mal.

Pernoctaron en mi pecho hasta que lució la faz del Este y los cabellos de las tinieblas corté.

No quedó nada para mí de sus rostros, a excepción del aroma del saquito de mirra que cogí.

Si hubiera sabido que el sueño iba a mostrarme los rostros de mis amigos, a los pies del sueño habría caído ${ }^{26}$.

$\mathrm{O}$ en los siguientes versos de otro poema suyo:

Los amigos, al exilarse, han partido lejos de mí, no están, aunque se encuentran en mis pensamientos.

Me han traicionado sus fantasmas, incluso cuando duermo temen acercarse a mí ${ }^{27}$.

El v. 52 de nuestro texto contiene también una imagen que utiliza Mošé ibn 'Ezrá en otros poemas, tanto de queja/amistad como amorosos, la de las «noches luminosas» en compañía de los seres queridos; y así lo encontramos, por ejemplo, en el siguiente verso de un poema de queja:

Mis días, oscurecidos sin mis amigos, lloran;

y antes las noches con el esplendor de su figura lucían, sonreían ${ }^{28}$;

y también en un poema amoroso:

Mis días sin mi amado son como su cabello, las noches pasadas con él como su rostro ${ }^{29}$.

${ }^{26}$ BRODY núm. 175 vs. 1-7.

27 BRODY núm. 13 vs. 13-14.

${ }^{28}$ BRODY núm. 200 v. 2.

${ }^{29}$ Días oscuros como el pelo negro, noches luminosas como el rostro radiante. BRODY núm. 147 v. 1. 


\subsection{Versos $59-60$}

El poema termina con unos versos en los que el poeta se ratifica en su amor por sus seres queridos, que no ha cambiado, y manifiesta su esperanza de que la amistad se renueve.

\section{RESUMEN}

La autora analiza y traduce al castellano el poema que comienza «Šabti vetaltalé zemán lo šabu» de Mošé ibn 'Ezrá (núm. 20 en la edición del diván de $\mathrm{H}$. Brody), el cual pertenece al género de los «poemas de queja» (širé teluná). Es precisamente en este tipo de poemas donde, a pesar del gran convencionalismo de la poesía hebrea andalusí, se puede encontrar mayor número de alusiones autobiográficas y rasgos personales de sus autores. En este caso Mošé ibn 'Ezrá nos presenta una visión de sus dos exilios: el que sufrió en Granada, su patria, después de la invasión almorávide; y el que padeció por tierras cristianas cuando se vio obligado a emigrar.

\section{SUMMARY}

The author analyses and translates into Spanish Mošeh ibn 'Ezra's poem «Šabti ve-taltalé zemán lo šabu» ( ${ }^{\circ} 20$ in the H. Brody's edition of the Diwan) that belongs to genre of complaint poems (siré teluná). Despite the great conventionalism of Hebrew Andalusian poetry, it is precisely in this sort of poems, where we can find the greatest number of autobiographical references and distinctive features of their authors. In this case, Mošeh ibn 'Ezra shows a view of his own experience in exile, first in his own land, Granada, after the Almoravid invasion, then in Christian Spain when he was compelled to emigrate. 